\title{
IDENTIDADE PROFISSIONAL DE PROFESSORES DE UM CURSO DE LICENCIATURA EM EDUCAÇÃO FÍSICA
}

\section{ARTIGO ORIGINAL}

NASSAR, Sérgio Eduardo ${ }^{1}$

MOREIRA, Wagner Wey²

NASSAR, Sérgio Eduardo, MOREIRA, Wagner Wey. Identidade profissional de professores de um curso de licenciatura em educação física. Revista Científica Multidisciplinar Núcleo do Conhecimento. Ano 04, Ed. 02, Vol. 02, pp. 112-141. Fevereiro de 2019. ISSN: 2448-0959.

\section{RESUMO}

O presente estudo objetivou analisar a(s) identidade(s) profissional(is) que os professores do magistério superior assumem no curso de Educação Física (EF), desenvolvido com 10 docentes que atuam em universidade pública. Trata-se de uma pesquisa qualitativa, com atitude fenomenológica, tendo como interrogativos: Qual(is) identidade(s) profissional(is) os professores do magistério superior de Castanhal/Pará, assumem no curso de EF? Os dados empíricos foram produzidos por meio de entrevista estruturada, pela Técnica de Elaboração e Análise de Unidades de Significado. Concluímos a identidade profissional do professor de Educação Física está relacionada a vários contextos.

Palavras-chave: Identidade Profissional Docente, Licenciatura em Educação Física, Docência Superior.

\footnotetext{
1 Doutor em Educação, Professor Adjunto II.

${ }^{2}$ Livre Docência e Doutor em Educação, Professor Titular III.
} 


\section{INTRODUÇÃO}

Os cursos de licenciatura em EF sofrem uma crise de identidade "[...] considerando o longo tempo de indefinição da mesma enquanto possibilidade científica" (MOREIRA, 2012, p. 113). Essa crise também atingiu os cursos técnicos em EF que visam o treino desportivo mesmo no âmbito escolar.

Percebemos que a área é fragmentada, e o exemplo disso são as experiências da nossa trajetória docente no acompanhamento dos alunos do curso de EF no Estágio Supervisionado. Enquanto as aulas propiciam primeiramente o pensar e, por conseguinte, a realização dos movimentos, o ensino da técnica esportiva é de forma mecanizada, sem incentivar a criatividade nas diversas ações que o corpo pode realizar. As atividades e os exercícios repetitivos visam a melhora da performance com intuito de treinamento específico em contextos diferenciados daqueles apreendidos na formação inicial.

Recorremos às ponderações de García (1999) ao destacar que, quando o professor desenvolve sua prática pedagógica isoladamente, sem intercâmbio com os seus pares, há probabilidade de fragmentar o conhecimento, o que tem acontecido comumente na área. Produzir um ensino com reflexão permanente sobre a prática é essencial, pois o que o professor pensa sobre o ensino tem influência na sua maneira de ensinar, e dá flexibilidade ou não às estratégias que projeta.

Apostar no reconhecimento de como o objeto de estudo da área vem sendo pensado ao longo da história nos parece ser uma opção valiosa para compreendermos como se configura a identidade profissional do professor de EF. Tanto que aprofundamos no levantamento das produções científicas produzidas nos cursos de pós-graduação sobre a temática proposta nesta tese, para apreciarmos os achados que elas apresentam.

Muitas vezes, o professor apresenta conteúdo sem nenhuma reflexão, e narram que, quanto à construção da identidade profissional, a formação inicial restringe a ação 
docente apenas à função de "ensinante", esquecendo-se de outras dimensões formadoras.

Assim o objetivo do estudo foi em saber: Qual(is) identidade(s) profissional(is) os professores do magistério superior de Castanhal/Pará, assumem no curso de EF? , buscando analisar a(s) identidade(s) profissional(is) que os professores do magistério superior de Castanhal/Pará assumem no curso de EF.

\section{MÉTODO}

O aporte metodológico deste artigo é de abordagem qualitativa porque se preocupa em analisar e interpretar a complexidade do comportamento humano (SEVERINO, 2007). O caráter qualitativo da pesquisa advém das vivências percebidas e expressas que os sujeitos trazem consigo.

Martins; Bicudo (1983, p.11) dizem que a fenomenologia é "o discurso sobre aquilo que se mostra como é (Phenomenos + Logos)", que parte de caminhos conhecidos de como fazer as coisas, mas que, ao mesmo tempo, desafia os pressupostos consagrados pela ciência que busca estabelecer um olhar norteado de teorias para ver o fenômeno estudado.

Assim, as vivências nos são dadas pelas expressões daqueles que as experienciam. Nesse sentido, é descrever o que narra o outro antes de qualquer reflexão científica, ponto-chave da pesquisa qualitativa de cunho fenomenológico. A fenomenologia tem sua ênfase no mundo enquanto é vivido pelo sujeito (BICUDO, 2011, p.38).

A pesquisa de campo constitui-se como a etapa em que os dados empíricos são produzidos "[...] em condições naturais em que os fenômenos ocorrem, para serem observados pelo pesquisador" (GUERRA, 2010, p. 11).

O locus eleito para a pesquisa foi a Faculdade de EF do Campus de Castanhal, da Universidade Federal do Pará, que dispõe de 15 professores com dedicação exclusiva (DE), mesclando com graduações diferentes, sendo 11 formados em EF, 2 pedagogos, 1 fisioterapeuta e 1 dentista. Todos são graduados em EF, e uma 
professora relatou que também possui a graduação em Pedagogia. Conforme os mesmos dados, identificamos, primeiramente, a idade dos participantes, com variações entre 27 e 48 anos, sendo: 2 sujeitos com 32 anos, 1 com 36 anos, 1 com 37 anos, 3 com 43 anos, 1 com 27 anos, 1 com 44 anos e 1 com 48 anos, sendo 5 professores do sexo masculino e 5 do feminino.

Marqueze e Moreno (2009), em estudos com professores universitários com média de idade de 39 anos, constataram que a idade não influencia no trabalho docente.

$\mathrm{Na}$ busca dos dados empíricos, usamos a entrevista com perguntas fechadas que foram respondidas pelos próprios entrevistados, e nos propiciaram o conhecimento do perfil dos sujeitos participantes (GAIO; CARVALHO; SIMÕES, 2008).

$\mathrm{Na}$ entrevista, interrogamos o sujeito por meio de duas questões geradoras: 1) Qual(is) identidade(s) profissional(is) você assume enquanto professor no Curso de EF do Campus de Castanhal?.

Para a realização dessa etapa, partimos para um contato prévio com os possíveis sujeitos, apresentando os objetivos da pesquisa, formalizando o convite e esclarecendo sobre o Termo de Consentimento Livre e Esclarecido (TCLE). Nesse momento, solicitamos que preenchessem o questionário, que nos garantiu o perfil de cada participante.

Para a organização do corpus da pesquisa nos apoiamos na Técnica de Elaboração e Análise de Unidades de Significado (MOREIRA; SIMÕES; PORTO, 2005), resultante da junção de duas envergaduras: a Análise do Fenômeno Situado visa a descrição, redução e interpretação dos dados, que resulta nas Unidades de Significado; e a Análise de Asserção Avaliativa busca identificar as atitudes dos sujeitos em relação ao objeto do qual falam.

A técnica utilizada apresenta três momentos: o relato ingênuo, a identificação de atitudes e a interpretação das informações sob a forma de discursos orais e escritos, que são vistos como indicadores significativos que atuam sobre a fala. 


\section{REFERENCIAL TEÓRICO}

Para mergulhar neste campo temático, Ciampa (1994, p. 127) diz que a "identidade deve ser vista não como uma questão apenas científica, nem raramente acadêmica: é, sobretudo, uma questão social, uma questão política", ou seja, para o autor a estrutura social mais ampla é a que oferece padrões de identidade, destacando aspectos sociais e institucionais na construção da identidade humana.

Na perspectiva apontada por García (1999), a identidade profissional do professor é elemento essencial para o desenvolvimento de suas atividades. $O$ termo profissional considera as variáveis intervenientes na efetivação do trabalho, que nada mais são do que o conjunto de ações e relações desenvolvidas pelos sujeitos que afetam o trabalho e propiciam a eles vivências de realização, afirmação, frustração, colegialidade, individualismo, representações, culturas, filosofias dotadas de potencial influenciador não só da configuração da identidade profissional, mas de outras formas identitárias.

Imbernón (2009) entende o profissional como aquele que domina uma série de capacidades e habilidades especializadas que o fazem ser competente em uma determinada atividade, e considera essa dimensão relevante na identidade social do indivíduo.

Assim, a identidade profissional também se configura como identidade coletiva, entendida como produto de um processo de várias socializações que acontece por dupla transação que o sujeito realiza: uma interna, dele consigo mesmo; outra externa, dele com o mundo. Essa identidade coletiva se constrói por meio das relações humanas: nasce do eu e se torna pessoal, porque é socialmente aceita (BRZEZINSK, 2002).

Para Lemos et al. (2002), a identidade profissional resulta da adequação entre a identidade para si e a identidade para o outro, sendo que os autores compreendem esse processo por meio da formação, do processo identitário biográfico e do processo relacional. As dimensões pessoais e profissionais não são possíveis de separar, 
porque a cultura, os saberes, as visões de mundo do profissional são que permitem essa construção.

Para tanto, é preciso compreender como os docentes reconhecem a sua identidade profissional para identificar como a formação inicial dos futuros professores de EF vem sendo construída, partindo do pressuposto de que são esses que constroem a compreensão da prática da EF.

A identidade profissional do professor de EF tem lastros pelos percursos históricos que marcaram a área. A EF no Brasil tem sua inclusão no currículo escolar a partir do século XIX, precisamente em 1851, com a reforma Couto Ferraz. Em seguida, em 1854, a ginástica é colocada como disciplina obrigatória no Ensino Primário ${ }^{[3]}$ e a dança, no Ensino Secundário ${ }^{[4]}$.

Dentro da construção histórica da área, a ginástica é considerada o primeiro conteúdo da EF escolar, porém, a consolidação da EF através dos Métodos de Ginástica na escola ocorre sob a influência de Rui Barbosa, com a Reforma de 1882, tendo o Método de Ginástica Sueco obrigatório para ambos os sexos, também oferecido nas Escolas Normais ${ }^{[5]}$ (DARIDO, 2003).

A EF tem também influência dos métodos ginásticos (século XVIII), em que os médicos constroem o conceito de corpo com saúde, robusto e harmonioso organicamente, concepção atrelada ao sentido de saneamento público, com o intuito de combater as doenças infecciosas e os vícios, em oposição ao corpo relapso, flácido e doentio do indivíduo colonial (CASTELLANI FILHO, 2003).

Após 1920, as escolas em todos os estados brasileiros passam a incluir a EF como disciplina obrigatória em seus currículos, mas só em 1930 é que a área inicia suas concepções ${ }^{[6]}$, sendo a primeira delas a higienista que influenciava todo o contexto educacional, tanto na disciplina escolar como na formação profissional.

A concepção higienista tem como foco a formação dos hábitos de higiene e saúde, pelo desenvolvimento físico e moral e por meio da prática do exercício físico. Para Gallardo (2000) essa concepção higienista assume conceito anátomo-fisiológico, 
influenciando a EF da época a adotar movimentos e gestos automatizados e disciplinados de um corpo saudável. $\mathrm{O}$ autor ainda ressalta que, exercendo um controle social sobre as famílias por meio da Medicina, é possível observar o discurso dos médicos com um tom disciplinador, normativo e moral, principalmente com enfoque na melhora da saúde física e mental.

Paralelamente à implantação da ginástica no contexto educacional, ela assume papel importante nas Escolas Militares, na preparação de uma geração capaz de suportar o combate nas lutas e guerras, com ênfase na seleção de corpos designados "perfeitos" em sua forma física, o que produz a concepção militarista, ainda presente nos dias atuais.

A partir de 1922, inicia-se a contratação de militares para atuarem como instrutores de ginástica nas escolas, período em que há a criação da primeira Escola de Formação de EF da Força Policial do estado de São Paulo, enfatizando o adestramento físico, para preparar a população ao cumprimento dos deveres cívicos na defesa da nação.

Ghiraldelli Júnior (1987) relata que a concepção militarista impõe à sociedade padrões estereotipados de comportamento, comuns na formação disciplinar utilizada nos quartéis, com o objetivo de uma juventude preparada para o combate, a luta e a guerra: é a ideia de uma EF com a finalidade de acelerar o processo de seleção natural de pessoal para o regime militar.

Um marco interessante acontece no período entre 1932 a 1946, tempo de renovação do ensino brasileiro sob a influência do movimento Escola Nova. A EF preconiza a educação do movimento, na formação integral do ser humano. Tanto que o Departamento de EF da primeira Escola Civil, criada pelo Governo do Estado de São Paulo, promove o primeiro concurso para profissionais da área, apontando a superação do conceito anátomo-fisiológico, nascendo, nesse cenário, a concepção pedagogicista (BETTI, 2009). 
Segundo Nascimento (1997), é o professor Inezil Penna Marinho ${ }^{[7]}$ que propõe o conceito bio-sócio-psico-filosófico para a EF, muito criticado por outros autores e grupos de pesquisa, por considerarem que sua obra retrata uma história positivista da área quanto à forma como dissertou a respeito da EF. Para Castellani Filho (2003), a homogeneização dessa história trouxe como consequência aos profissionais a reprodução de vários conceitos e abordagens que influenciaram a área por mais de quatro décadas.

Em 1966, inicia-se a concepção esportivista, tendo como foco a EF, o esporte, principalmente a competição para promover no indivíduo condutas como solidariedade, tolerância, lealdade, a formação do caráter humano (BETTI, 2009).

Todo esse movimento é de via política, é o Estado quem propõe o binômio EF e Esporte. A frase demarcada nesse período foi: "Esporte é saúde", que traz para o profissional professor prejuízo alto, por ter de atuar como instrutor (denominado, na época, de professor-treinador), fato que faz com que a EF seja uma prática de treinamento árduo, doloroso e cansativo (DARIDO, 2003).

Ante essa deflagração de entendimentos sobre as intenções da área, sempre uma interrogação permanece: o que é a EF? Quais seus princípios enquanto área de conhecimento? Nessa direção, Oliveira (2008) apresenta suas reflexões, quando relaciona a EF com a ginástica que foi predominante no contexto histórico brasileiro devido aos métodos europeus existentes. Reflete ainda se a área é da saúde, sob influência da Medicina, principalmente por terem os currículos da formação profissional um número expressivo de disciplinas da Biomedicina, o que faz com que o profissional atualmente possa ser reconhecido como "educador físico".

Mas, notamos que o autor não define o que vem a ser a $\mathrm{EF}$, sendo que a sua proposta era apontar o conceito desta área. Outro questionamento seu: a EF é cultura ou é jogo? Cultura devido às suas características, ou esporte, em vista do tecnicismo. Por fim, é provocativo: a EF é uma Ciência?, que traduz a maior problemática da área nos dias atuais. Não é compreendida como ciência, embora o autor a defenda como tal, tendo como objeto de estudo o corpo em movimento. 
Após 1980, a EF é circundada por outras tendências que desencadeiam uma crise de identidade que, historicamente, vem refletindo na área. É nesse contexto que cresce a oferta de cursos de pós-graduação; várias pesquisas e estudos ressaltam as chamadas abordagens pedagógicas que analisam e são propositivas quanto à ação profissional do professor, principalmente no contexto escolar.

É possível identificar os esforços no sentido de desvelar a ação pedagógica. Por outro lado, há pouco empenho na direção dessas abordagens por não terem a preocupação de identificar o objeto de estudo da área; o máximo de compreensão que algumas apontaram foi sua matriz epistemológica. Isso ratifica nossa discussão sobre o aprofundamento das identidades profissionais da área e não da ação profissional do professor que atua com a EF.

Darido (2003) destaca que o objetivo das abordagens é de romper com o modelo tecnicista soberano na área. Reconhece dois momentos dessas: em um primeiro movimento, aparecem a Psicomotricidade, a Desenvolvimentista, a Construtivistainteracionista, a Crítico-superadora e a Sistêmica; no segundo movimento, aparecem a Crítico-emancipatória, a Cultural, os Jogos Cooperativos, a Saúde Renovada e os Parâmetros Curriculares Nacionais (PCNs).

Citamos essas abordagens apenas porque consideramos que, provavelmente, muitos docentes podem se identificar com algumas destas apresentadas. No entanto, deixamos claro que elas não se destinam a questionar, ou mesmo criar uma identidade ou refletir sobre as bases epistemológicas da área de conhecimento denominada EF, razão pela qual não nos propusemos a dissertar sobre essas abordagens mencionadas por Darido (2003).

Essa crise de identidade profissional da EF e de seu objeto de estudo tem a ver com o que Dubar (2009, p.25) defende, quando uma área tem sua identidade indefinida: isso "[...] provoca uma crise que traz para área de conhecimento configurações de discursos, de atitudes, de narrativas puramente contingentes, totalmente dependentes de seu contexto de produção", o que ocorre nesta área. 
Entendemos que, em todo esse percurso evolutivo da área, possivelmente já obtivemos pistas que apontaram uma identidade para este campo de estudo, e apresentamos, a seguir, 5 teorias que são relevantes para a compreensão do objeto de estudo da EF e sua identidade própria.

Afinal, quem foi José Maria Cagigal[8]? Com oito obras publicadas referentes à EF e Esporte, da sua produção acadêmica, analisamos as Obras Selectas, volume I, II e III, para a compreensão do que o autor busca explicitar sobre o entendimento de EF e de Desporto ${ }^{[9]}$ enquanto área de conhecimento científico.

Seu objeto de investigação está relacionado ao desporto, no levantamento dos autores que tentam apresentar suas definições para a temática. Cagigal (1996, p.19) admite que foram "os provenzales quienes emplearon por primera vez de una manera ya definida la palabra deporte, en el sentido de divertimiento, distracción recreativa". O sentido da palavra provém dos marinheiros que, nas horas vagas, utilizavam atividades motoras para divertimento, alegria e entreterimento, ocupação do ócio por meio de atividades como jogos de azar.

Pela visão do autor, acreditamos que suas propostas, reflexões e conceitos são pertinentes à área da $E F$, sugerindo que o esporte deva ser uma atividade prévia à organização social e que traga possibildade aos sujeitos de participação e não de exclusão, a ponto de extirpar de muitos a vontade e o prazer de uma vida ativa.

A Teoria Praxiológica é elaborada por Pierre Parlebás ${ }^{[10]}$, que apresenta uma Ciência denominada de Praxiologia Motriz, e tem como proposta um "estudo coerente e unitário agrupando todos os dados pertinentes que dizem respeito ao seu objeto específico [...], visando constituir um campo, o campo da ação motriz". Tem também várias publicações em diversos idiomas (PARLEBÁS, 1988, p. 173).

Acredita que a EF deva ter seu enfoque na Teoria Sociomotriz, desenvolvendo como estudo os jogos desportivos institucionais e os esportivos tradicionais, para analisar o valor e a dinâmica de cada modalidade. No final da década de 1960, inicia suas 
primeiras publicações sobre a Praxiologia: lá se vão mais de trinta anos para desvendar o mundo dos jogos, esportes, brincadeiras e exercícios físicos.

Nessa ótica, a Praxiologia Motriz facilita a organização dos conteúdos a serem aplicados nas aulas de EF. A teoria de Parlebás (1988) ressalta que a função deste professor visa a orientação da prática do jogo, ou seja, intervenção a todo momento, propiciando relações que tenham significado na vida dos praticantes e não apenas o jogar por jogar; que os sujeitos envolvidos, enquanto atores e espectadores, possam usufruir daquilo que o jogo proporciona ao ser humano.

A Teoria da Psicocinética foi estruturada por Jean Le Boulch ${ }^{[1]]}$, com foco no desenvolvimento global das potencialidades de uma pessoa, que não se resume tão somente ao aspecto motor; tanto que analisou o desenvolvimento orgânico e emocional que se refletem na identidade e nas qualidades das relações do ser humano.

A contribuição das concepções fenomenológicas e etológicas no campo das ciências humanas é considerar a ciência biológica, com ênfase na neurociência, ou seja, entender o ser humano a partir das suas condutas motoras, mas estudando o sistema nervoso, sua estrutura, o desenvolvimento e o funcionamento, sua evolução a partir dos comportamentos e ações.

A Ciência da Motricidade Humana (MH), defendida por Manuel Sérgio, tem o propósito de dar um corte epistemológico no racionalismo, do qual nasceu a EF, e que está definitivamente ultrapassado. Esta ciência visa superar o significado da $E F$, visto que seus conceitos e valores presentes substituiriam a ordem anterior presente na área por uma desordem aparente, a qual levaria a uma nova ordem.

Assim, apresenta uma proposta de ciência que está entre nós há quase três décadas, com o objetivo de dotar a EF de uma identidade própria no campo da ciência, possuindo um objeto de estudo definido. Esta é a Ciência da Motricidade Humana $(\mathrm{MH})$, idealizada por Manoel Sérgio Vieira e Cunha ${ }^{[12]}$. 
Destaca que a EF é a pré-história da Ciência da Motricidade Humana e que deve estudar 0 ser humano que se movimenta intencionalmente na direção da autossuperação. Sua tese volta o olhar ao ser humano, precisamente ao corpo.

Sérgio (1995; 1999; 2003; 2008) junta-se àqueles pensadores que acreditam que o ser humano deve ser visto em sua totalidade. Define ainda que a Ciência da $\mathrm{MH}$ )(MHvisa compreender como as ações motoras lançam energia para o movimento intencional, buscando especialmente a transcendência e a superação.

A MH convida a cultivar a totalidade humana pelo corpo, pelo espírito, pela natureza, a sociedade e a cultura, não somente pela ação objetiva ou pelo desenvolvimento motor. Compreendemos, nesta proposta, que o corpo é, a um só tempo, genético, bioquímico, fisiológico, cultural, social e psicológico.

Ainda como propositura de Manuel Sérgio, encontramos o termo Educação Motora, definida pelo autor como o ramo pedagógico da Ciência da Motricidade Humana, tendo como objetivo a preocupação pedagógica de ensinar o que a área de conhecimento produz. A Educação Motora seria, num primeiro momento, praticamente sinônima da EF Escolar. Afirmamos "praticamente" porque pode haver Educação Motora fora da escola, e aparece sempre que a preocupação pedagógica do professor é superior à preocupação técnica.

A Ciência do Desporto constitui uma teoria proposta por Jorge Olímpio Bento ${ }^{[13]}$ e outros docentes da Universidade do Porto, a qual pode muito bem operacionalizar propostas pedagógicas para o interior da educação.

Quanto à Ciência do Desporto, Bento (2006, p. 155) a define como "um conjunto de tecnologias corporais, sendo o uso destas balizado por razões e padrões culturais e por intencionalidades, metas e valorizações sociais", além de nos alertar que a sociedade pós-moderna, via novas tecnologias, está se caracterizando por imprimir nos corpos humanos afisicidade ${ }^{[14]}$, aumentando o predomínio da mente sobre o corpo, da atividade mental sobre a motora. 
O desporto visa cuidar do corpo, da alma e de tudo aquilo que seja direcionado à dimensão humana, tanto nas questões do seu interior quanto do exterior, do individual quanto do coletivo, do objetivo e do subjetivo, possibilitando o que Moreira (2006) perspectiva: o envolvimento com a arte de viver e conviver.

A compreensão das palavras "atividade física" e "saúde"[15] vem sendo dirigida somente à dimensão física, mas aponta que "os atos desportivos e tantas outras expressões e modalidades da cultura motora e da exercitação corporal - somente são físicos na aparência" (BENTO, 2012, p.7). Por isso, o autor entende que o desporto tem a sua dimensão física, mas não se limita a essa questão.

Assim, as atividades esportivas, lúdicas e corporais têm seu caráter multifuncional para a compreensão do significado do esporte. Por ele o ser humano encontra portas para as vivências do jogo, da competição, do rendimento, do medo, da comunicação e da cooperação, do convívio, da intimidade, da sociabilidade, que emergem da essência humana, porque o corpo é ser presente no mundo do esporte.

Para tanto, os professores universitários que atuam no curso de EF e Esportes devem ser os cientistas, teóricos e práticos que têm a responsabilidade de reunir os conhecimentos da dimensão humana e trazer para a sala de aula, por meio de discussões e conceitos voltados a formar o futuro professor que atua com o corpo/corporeidade.

\section{ANÁLISE E DISCUSSÃO}

Após delinearmos os indicadores, estabelecemos as Unidades de Significado que associamos com o referencial teórico apresentado, procurando identificar pontos de convergência e divergência, qualificando possíveis interpretações sobre o fenômeno pesquisado. Por meio da fala dos professores universitários, compreendemos como eles reconhecem a identidade profissional do professor e da área de conhecimento da EF. 
A partir dos indicadores, ilustramos, com um quadro, as unidades de significados encontradas na percepção dos pesquisadores sobre o fenômeno em estudo.

Quadro 3 - Unidades de Significado da Questão 1 - Qual(is) identidade(s) profissional(is) você assume enquanto professor no Curso de EF do Campus de Castanhal?

\begin{tabular}{|c|c|c|c|c|c|c|c|c|c|c|c|}
\hline $\begin{array}{l}\text { Sujeitos } \\
\text { Unidades }\end{array}$ & 1 & 2 & 3 & 4 & 5 & 6 & 7 & 8 & 9 & 10 & $\begin{array}{l}\text { Frequência } \\
\text { (F) }\end{array}$ \\
\hline $\begin{array}{l}\text { Relaciona a identidade à questão } \\
\text { do corpo, dos grupos sociais, da } \\
\text { sociedade, das práticas corporais } \\
\text { e dos campos de atuação da EF. }\end{array}$ & $x$ & $x$ & & $x$ & & $x$ & & & $x$ & $x$ & 6 \\
\hline $\begin{array}{l}\text { Assumem, em sala de aula, uma } \\
\text { identidade profissional de } \\
\text { envolvimento com as questões } \\
\text { sociais, filosóficas e humanas. }\end{array}$ & & $x$ & & $x$ & $x$ & $x$ & $X$ & & & $x$ & 6 \\
\hline $\begin{array}{l}\text { Identidade Profissional } \\
\text { Pedagógica enquanto educador. }\end{array}$ & & $x$ & & $x$ & $x$ & $x$ & $X$ & & $x$ & & 6 \\
\hline $\begin{array}{l}\text { O processo de construção da } \\
\text { identidade profissional é marcante } \\
\text { a partir da atuação na docência, do } \\
\text { ato de ensinar. }\end{array}$ & $x$ & & & $x$ & $x$ & & & & $x$ & $x$ & 5 \\
\hline $\begin{array}{l}\text { Compreende a identidade } \\
\text { profissional a partir da discussão, } \\
\text { em sala de aula, sobre o } \\
\text { distanciamento teoria e prática e a } \\
\text { vivência do discurso do docente na } \\
\text { prática. }\end{array}$ & & & & & $x$ & $x$ & & $x$ & $x$ & $x$ & 5 \\
\hline $\begin{array}{l}\text { Assume uma identidade advinda } \\
\text { da experiência voltada ao esporte, }\end{array}$ & & & $x$ & $x$ & & & $X$ & $x$ & & & 4 \\
\hline
\end{tabular}




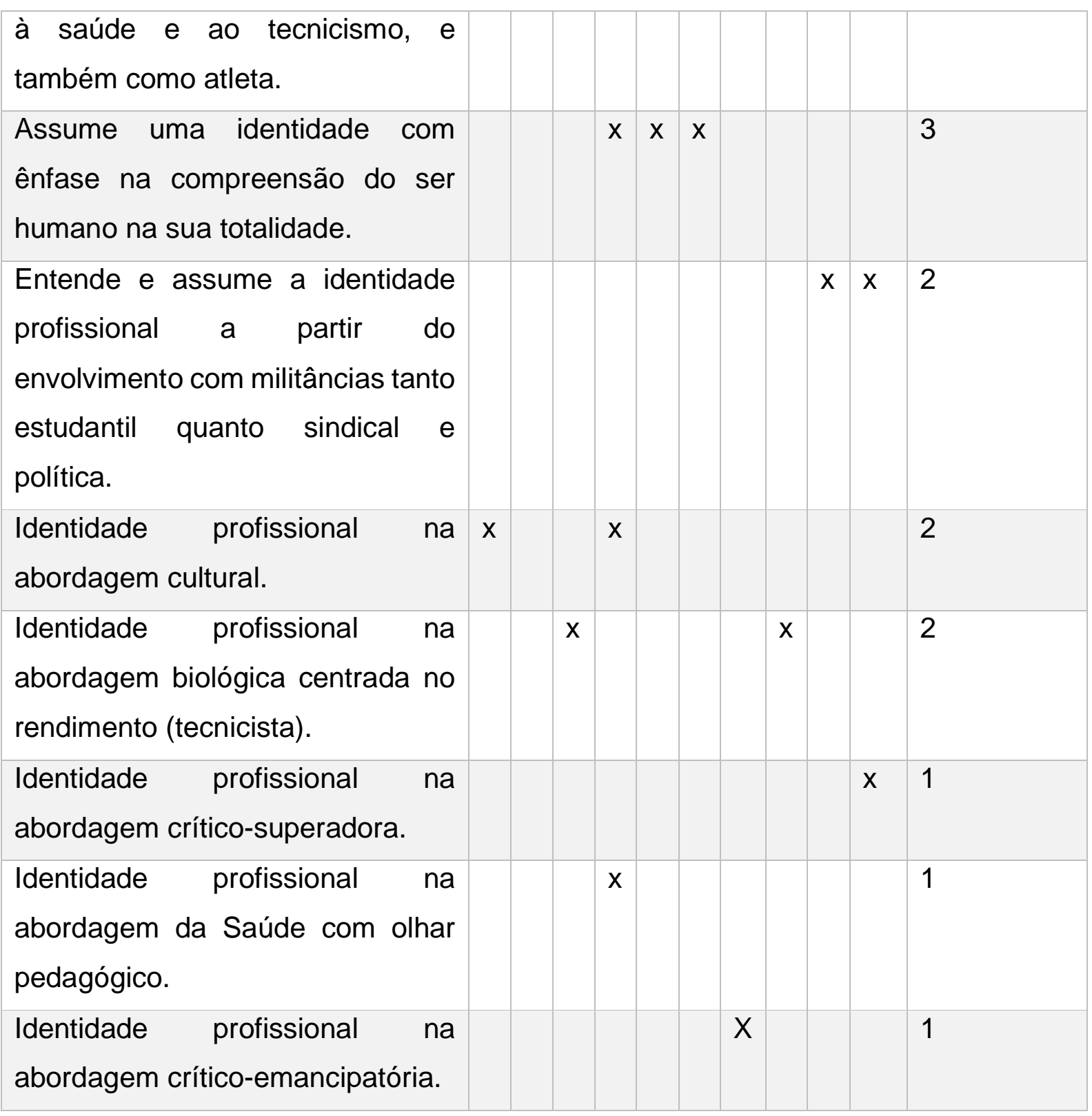

Fonte: Dados produzidos a partir da entrevista realizada com os docentes.

A análise ideográfica constitui-se como a interpretação do pesquisador a respeito dos discursos e, na análise nomotética, o destaque segue para os pontos de convergências e divergências entre os sujeitos com base, principalmente, no referencial teórico de alicerce para o estudo.

Os dados da pesquisa desvendam que uma das unidades de significado de maior relevância na fala dos sujeitos, enquanto identidade profissional do professor de EF, 
é a de relacionar a identidade à questão do corpo, dos grupos sociais, da sociedade, das práticas corporais e dos campos de atuação.

Essa identidade profissional se mostra nas concepções adotadas pelo docente em sala de aula, como observamos na fala do sujeito 6, que diz: "[...] então, buscando principalmente levar algumas discussões teóricas para os alunos, que dão conta de mostrar as várias perspectivas e as várias linhas que a EF tem, não se restringindo apenas em conhecimento em uma dessas linhas [...] ", contextualizando que esta identidade é ampla, tendo raízes em várias outras áreas do conhecimento.

Para tanto, é preciso que o docente procure promover nas suas aulas condições para que isso ocorra, incentivando a produção do conhecimento por meio de estratégias de ensino de forma diversificada e diferenciada, como ressalta o sujeito 9: "[...] assumindo as disciplinas [...], entre outras coisas, tinha a questão dos espaços não escolares: entrava academia, entravam os clubes esportivos, [...] para continuar fazendo discussão da docência mesmo nesses espaços".

Interpretamos essa fala do professor como referência àqueles saberes que estão ligados a uma situação de trabalho e ancorados nas tarefas mais complexas encontradas nos espaços onde venha a atuar, por meio da sua experiência de vida e sua história profissional.

Entendemos que a docência, ao transmitir conhecimentos, o faz colocando todas as suas percepções e experiências advindas daquilo que também vive como pessoa.

Os discursos dos sujeitos 2, 4, 5, 6, 7 e 10 mostram que os docentes assumem, em sala de aula, uma identidade profissional de envolvimento com as questões sociais, filosóficas e humanas. Tanto é que o sujeito 2 adota, na prática pedagógica, esses saberes, quando afirma que os docentes "[...] acabam assumindo uma função de trazer o conhecimento da área da EF para dentro da sala de aula, associado às dimensões sociais, filosóficas que envolvem todo esse campo".

O sujeito 6 revela: "as discussões que eu tenho feito com os alunos é exatamente nessa perspectiva, na formação de professores que possam atuar [...] tanto em 
espaços escolares e não escolares, compreendendo esse homem na sua totalidade e[...] contribuindo na formação destes alunos no aspecto tanto teórico, quanto prático, quanto sociopolítico, comprometido com a questão social e humana". Assume que a EF compreende o ser humano que se movimenta intencionalmente na busca da superação por meio de movimentos relacionados às atividades cotidianas.

Cagigal (1996, p. 112) entende que "educar es algo mucho más vital que instruir", e isso se faz por meio de duas ações: melhorar o ser humano em relação às suas atitudes e objetivos, proporcinando um processo de desenvolvimento; e educar as realidades econômicas, políticas, patrióticas, sociais, artísticas, estéticas, sentimentais (paixões e coração).

Segundo o sujeito 2, cabe ao docente que atua no Ensino Superior, com as disciplinas da área, procurar "[...] despertar o aluno para a atualidade do campo da $E F$, fazendo as relações entre o corpo e a sociedade, entre as identidades de grupos sociais e a relação disto com o corpo, com as práticas corporais". Este é um dos maiores desafios para os que atuam na formação inicial e continuada, porque, nesta esteira, estamos proporcionando ao discente a reflexão sobre a prática e a compreensão do campo de atuação.

Notamos que 6 docentes assumem uma identidade profissional pedagógica enquanto educador, sendo os sujeitos 2, 4, 5, 6, 7 e 9. Todo docente, às vezes sem se dar conta, assume, no campo da formação inicial de futuros professores que atuarão no campo da $E F$, discussões pautadas naquilo que é relevante à sociedade e ao que o discente encontrará em sua prática pedagógica. Este fato faz entender o docente como ator desse contexto.

Não é um modelo ou forma a ser colocado em ação, porque nasce e se constitui em um processo de construção, evolução e aperfeiçoamento do fazer humano. Para a autora, forma/ação têm significado no sentido de ação que se configura na formatação da imagem e da ação, movimento que atua na forma. 
No contexto escolar, é compreendida como processo de ensino-aprendizagem (orientação, direção), o que a torna complexa pois, muitas vezes, envolve fatores de ordem sem precisão, mas que, por outro lado, abrange aspectos subjetivos referentes a valores, atitudes, hábitos, juízos, desejos, ideia, conceitos, símbolos a serem apreendidos no continuum da formação, processo que "[...] diz respeito a indivíduos situados no mundo espaço-temporal, sujeitos historicizantes" (BRZEZINSKI, 2002, p. $66)$.

A fala do sujeito 9 converge para esses argumentos: "docência [...] essencialmente eu tenho convicção de que eu sou um professor, de que eu sou um docente, de que esse é o perfil da nossa atuação, seja no campo escolar, seja no campo não escolar". Independentemente do espaço, formar não se resume em passar conteúdos por meio do ensino, mas buscar soluções também coletivas para os problemas encontrados na vida: é um processo permanente e indissociável das ocorrências cotidianas.

O ser humano vive em processo contínuo de formação (GARCíA, 1999), por ter que saber-fazer ou saber-ser em vários momentos e etapas da vida. Como diz o sujeito 5 : "[...] eles se sentindo educadores e eu me sentindo também uma educadora mais humanista"; esta é a função social do professor que atua na construção da formação de sujeitos que estejam preparados para a vida e não somente para a prática profissional.

Um aspecto que chamou nossa atenção em relação à formação inicial e a construção da identidade docente é o das experiências obtidas na graduação, conforme descreve o sujeito 4: "e aí, eu fui me percebendo num processo pedagógico, num processo de ensinar, disponibilizar um conhecimento que eu já trazia, e socializar esse conhecimento; ali eu já comecei a desenhar a minha trajetória, atuando na EF; então, eu venho com essa preocupação de levar contribuições da EF ou trazer as contribuições da EF através da saúde, das prevenções, mas me debruçando no pedagógico".

A vida dos professores, suas experiências, suas vivências e sua relação com a história do seu tempo permitem sua inserção e sua relação com a sociedade, com as 
escolhas, contingências e opções que eles fazem em sua carreira profissional (GOODSON, 2000).

A pesquisa evidencia outra unidade de significado, de que processo de construção da identidade profissional é marcante a partir da atuação na docência, do ato de ensinar: muitos professores só conseguem percebê-la a partir da atuação como docente no Ensino Superior, o que demonstra que o término da graduação não garante que este profissional se aproprie de uma identidade pré-definida.

Brzezinski (2002), André (2002), Guimarães (2004) relatam, por meio de seus estudos, que, ao adentrar na identidade profissional, há que investigar a profissionalidade docente, porque esta permite compreender como se constrói a identidade profissional do professor.

Notamos que o sujeito 1, por apresentar uma outra formação, em Pedagogia, com a qual esteve muito envolvido, assume: "eu atuei muito na área da educação, então, [...] eu assumi uma identidade mais ligada à educação, nas disciplinas que eu ministrava", o que corrobora com o que os autores acima dizem, que a atuação docente propicia reflexão sobre a sua ação profissional enquanto professor.

A identidade é construída e mantida socialmente de acordo com concepções que o docente adota enquanto base epistemológica, isto é, compreender a identidade profissional, a partir da discussão em sala de aula sobre o distanciamento teoria e prática e a vivência do discurso do docente na prática, outra unidade de significado revelada pelos docentes, e que nos conduz à fala do sujeito 8: "na minha identidade, eu procuro ter um discurso em que a minha prática tem que ser condizente com o que eu falo".

Ressaltamos essa fala, para compreender que a área de conhecimento EF consiste em ciência, teoria e prática, não havendo como desmembrar este tripé de embasamento.

A EF tem assumido, mais acentuadamente, duas posições epistemológicas na produção do conhecimento: uma composta por docentes que privilegiam os motes 
teóricos da Biomecânica e da Biologia, de base positivista e mecanicista; outra assumida nas dimensões psicológicas, antropológicas, sociológicas, históricas, fenomenológicas e culturais do movimento, refletidas na $\mathrm{MH}$ que objetiva habituar o aluno a pensar de forma radical, crítica e sistêmica (SÉRGIO, 1999).

É preciso desconstruir a ideia da prática como critério único de verdade, e considerar que não há como discutir teoria por teoria numa área em que o corpo em movimento intencional busca a transcendência e a superação: a prática sem a teoria direciona à rotina

A MH é pedagógica porque tudo se estuda interdisciplinarmente, entendendo que tudo é processo. Infelizmente no campo da docência, encontramos profissionais que não procuram discutir, planejar, dialogar, sistematizar e problematizar com seus alunos sobre os conteúdos específicos da área: são simplesmente reprodutores de uma rotina de atividades e exercícios.

Nos dias atuais, muitos docentes da área EF passam a identificar-se com a prática pedagógica a partir da vivência e da experiência com o exercício físico, enquanto profissionais ou não. Os dados em cena demonstram docentes que assumem uma identidade advinda da experiência voltada ao esporte, à saúde e ao tecnicismo e também como atletas, portanto, outra unidade de significado.

Vejamos a fala do sujeito 3: "[...] o fato de ter sido atleta, ter feito atividade física durante toda a minha vida [...] ter a experiência profissional, fico mais voltado consequentemente para essa área esportiva; [...] foi a minha experiência prática, toda a minha formação". Notamos que a identidade é resultado de experiências, que sua definição é polimorfa, sujeita a mudanças, tanto que este docente apresenta sua identidade vinculada às histórias que protagonizou ao longo do tempo.

Mesquita et al. (2012) ressaltam que docentes que tiveram a experiência como atletas e, em seguida, iniciam com a docência superior, precisam desvencilhar-se da abordagem tradicional positivista e debruçar-se sobre abordagens mais recentes, pois esse envolvimento como atleta propicia uma identidade profissional de futuro treinador 
no campo da EF. No entanto, os futuros egressos de uma graduação buscam desenvolver a identidade reproduzindo o que aprenderam, na sua formação acadêmica, dos docentes treinadores. Os mesmos autores relatam que um docente com matriz conceitual na perspectiva tradicionalista tende para uma linha de pensamento fragmentada, e, atualmente, não mais suportada pelo conhecimento científico.

Notamos que, nesta unidade, os sujeitos 3, 4, 7 e 8 apresentam um envolvimento atual com a área, advindo das experiências práticas em suas histórias de vida, tanto que o contextualizam nessa trajetória para justificar sua movimentação profissional na EF.

Os resultados da pesquisa demonstram que a Identidade Profissional dos docentes é apresentada em duas unidades que associamos para análise, sendo os que assumem uma identidade com ênfase na compreensão do ser humano e na sua totalidade. Realizamos a análise desta unidade de significado, considerando a compreensão de ser humano e associando, ainda, as discussões da $\mathrm{MH}$ que direciona pelos caminhos do humanismo.

Os sujeitos 4, 5 e 6 assumem uma identidade profissional, visando essa percepção do ser humano, como afirma o sujeito 5: "[...] uma identidade humanista", que corresponde a olhar para a totalidade da essência humana. Nas entrelinhas, acreditamos que esses achados dialogam com as bases epistemológicas da $\mathrm{MH}$.

O sujeito 6 admite: "[...] eu me pauto na questão da corporeidade da $M H$, e as discussões que eu tenho feito com os alunos são exatamente nessa perspectiva, na formação de professores, compreendendo esse homem na sua totalidade e com isso também buscando contribuir na formação destes alunos [...] a ter esse perfil como professora dentro das minhas disciplinas".

Para este docente, sua identidade é pautada na matriz epistemológica que o curso de EF do campus de Castanhal adota em seu PPC, que é a da MH.

Outra unidade de significado reconhecida na fala dos docentes foi entender e assumir a identidade profissional a partir do envolvimento com militâncias, tanto estudantil 
quanto sindical e política, principalmente para os sujeitos 9 e 10 que assumiram o processo de construção da sua identidade docente, permeado por essas experiências.

O sujeito 9 reflete: "[...] isso se fortaleceu como consequência desse casamento, entre aquilo que eu já fazia na militância. Na EF [...] eu tinha obviamente que não apenas ficar no discurso de militante, mas no discurso acadêmico-científico, para poder fazer a formação dos alunos em sala de aula; sobre essa relação, a gente aprofunda as reflexões: porque academia, porque clube, porque hospital, outros espaços em se que caracteriza o trabalho do professor de EF".

Os dados em cena revelam vários docentes apontando a identidade profissional enquanto abordagens pedagógicas da área da EF, as quais surgiram na década de 1970, para contextualizar a ação pedagógica, principalmente no campo escolar. Percebemos que 2 docentes assumem a identidade profissional na abordagem cultural; 2 ressaltaram a identidade profissional na abordagem biológica centrada no rendimento (tecnicista); 1 aponta a identidade profissional na abordagem críticosuperadora como opção; 1 afirma sua identidade profissional na abordagem da Saúde com olhar pedagógico; 1 assume a identidade profissional na abordagem críticoemancipatória e, por fim, 1 revela uma identidade humanista.

Concluímos que os docentes, sujeitos da pesquisa, têm dificuldade em reconhecer o objeto de estudo da EF, uma vez que apontam as abordagens pedagógicas como identidade profissional que assumem no contexto de sala de aula.

As abordagens pedagógicas são frutos do investimento de autores para explicar a ação profissional do professor de EF, com ênfase naqueles que atuam no campo escolar. É necessário localizar o objeto de estudo da área numa defesa epistemológica das teorias mencionadas anteriormente nesta tese - Teoria Antropológico-Cultural do Esporte e da EF, Teoria Praxiológica, Teoria Psicocinética, Ciência da Motricidade Humana e Ciência do Desporto.

Quando os professores apontam interpretações diferentes para suas identidades profissionais, como no caso dos entrevistados, isso se traduz no que Dubar (2009) 
defende de que uma área que não tem a sua identidade definida inicia uma crise que proporciona formas de discursos, atitudes, narrativas analisadas isoladamente do seu contexto de produção.

Conforme a técnica utilizada essa propõe que busca-se uma análise nomotética da identidade profissional do professor de Educação Física. Neste momento da pesquisa, é necessário um olhar diferenciado aos discursos dos sujeitos, caminhando para uma apreciação mais geral que, de acordo com Moreira; Simões; Porto (2005) é o movimento de "insights gerais", de analisar a estrutura do pensamento individual que pode convergir para ideias de outros sujeitos. $\mathrm{Na}$ análise nomotética, o destaque segue para os pontos de convergências e divergências entre ideias dos sujeitos, com base principalmente no conhecimento científico.

Uma convergência entre os docentes está em assumir a identidade profissional, entrelaçando a questão do corpo, dos grupos sociais, da sociedade, das práticas corporais e dos campos de atuação, revelando aquilo que eles atribuem e conceituam enquanto compreensão do ser humano que se movimenta intencionalmente em busca da superação.

Cagigal (1996) assinala em suas obras que, para o docente, a EF deve ser compreendida como uma arte, uma ciência, um sistema de técnicas para que o ser humano aprenda, por meio do movimento corporal, a aumentar suas potencialidades, proporcionando um diálogo harmonioso com a vida, ou seja, ela deve ser um sistema educativo, visando uma atitude transcendental.

Compreendemos que definir a identidade profissional não é tarefa breve, porque, no seu cotidiano, os docentes promovem na sala de aula o envolvimento com questões sociais, filosóficas e humanas, marcadas por aquilo que se constitui fruto da relação que estabelecem com o mundo e com as pessoas. A todo o momento, no ato educativo, apelamos para as nossas referências teóricas, afetivas, sociais, culturais, das quais não temos como nos desprender. 
Essa perspectiva favorece ao discente despertar sua capacidade crítica na prática cotidiana da formação, a realizar reflexões sobre o contexto em que ela ocorre, transformando, quem sabe, esse sujeito que está envolvido com o processo educativo.

De acordo com Zeichner (1993), na reconstrução social, o professor é autônomo, porque pode refletir criticamente sobre a sua prática profissional no dia a dia, alimentando seu potencial de criação e amadurecimento no processo de formação dos seus discentes e no alcance dos objetivos propostos na sua disciplina.

A EF, na produção de conhecimento, dialoga com outras áreas de conhecimento, mas esqueceu-se de sua autonomia, de pensar epistemologicamente e identificar seu objeto de estudo próprio, como alertamos sobre as experiências voltadas ao tecnicismo e à carreira de atleta, contextualizadas em sala de aula de forma pragmática.

A identidade profissional percebida e assumida enquanto um educador se faz essencial para a atuação do docente. Esse é um investimento com o qual o professor de EF deveria se preocupar na formação inicial dos seus alunos, em diferenciar ser professor de ser instrutor em sala de aula, que é a grande preocupação dos docentes, revelada pelos dados.

Não é a modelagem de um profissional que cabe à Educação Superior, mas o desafio de uma formação que dê condições do futuro egresso lidar com problemas e situações diversas que podem ocorrer nos espaços profissionais, sabendo dialogar e encontrar soluções para resolvê-los juntamente com seus pares. Entendemos que, muitas vezes, há questões que a formação inicial não consegue discutir ou sequer apresentar e direcionar soluções.

A maior divergência na docência é quando o docente não assume a sua identidade enquando educador: ele passa a ser um instrutor, propiciando ao discente conflitos entre o que foi "ensinado e treinado", no processo da formação inicial, com a realidade que encontrará na sua prática profissional (AMIGUINHO et al., 2003). 
O docente compreende que há questões da prática profissional que a formação inicial não abrange em sua complexidade. Mas, a partir dos anos na carreira profissional e por meio dos saberes experenciais, poderá superar as lacunas e déficits que haverão de surgir na prática pedagógica do profissional.

Os docentes indicam que a construção da identidade profissional é marcante a partir da atuação na docência, no ato de ensinar. Percebemos que é preciso trazer referências para o elo entre saberes teóricos e práticos, em que se constrói como ser professor, e se defendem teorias que justifiquem suas opções metodológicas. É esse fluxo na carreira que faz justamente com que a identidade não seja fixa ou imutável.

Corroborando com essa defesa, Pereira e Martins (2002) dizem que a identidade profissional é construída no exercício das atividades cotidianas do docente, com sustentação nos saberes específicos, pedagógicos e experienciais, apanhados dentro e fora da sala de aula, num continuum. Os saberes da experiência são produzidos no cotidiano docente, a partir das vivências no espaço pedagógico, sejam as salas de aula, os laboratórios de práticas corporais, as quadras ou piscinas. Cabe ao docente concretizar, na formação inicial, uma mudança, a de fazer a passagem deste aluno, para que possa se ver como professor, como observamos na fala do sujeito 5 que os discentes sintam-se professores.

O docente, ao receber uma turma que ingressa no primeiro ano da graduação, e ao perceber a visão que esses discentes trazem sobre a área $E F$, tem o desafio de transformar essa forma de pensar as questões epistemológicas que demarcam a área. Muitas vezes, eles trazem consigo ideias voltadas especificamente à prática de esportes, e poucos sabem que os conteúdos da EF os conduzirão a teorias, vivências sobre esportes, ginástica, jogos, dança e lutas.

Tanto que os dados convergem, quando a identidade profissional é compreendida a partir da discussão, em sala de aula, sobre o distanciamento teoria e prática e a vivência do discurso do docente na prática; é um desafio necessário para o professor sustentar essa discussão teoria e prática, para que o futuro egresso lide com as situações de complexidade da profissão. 
Nesse sentido, Tardif $(2000 ; 2002)$ apresenta uma classificação de que todo docente deve ter conhecimento e utilizar em sala de aula: são os saberes disciplinares, curriculares e experienciais essenciais para a atuação.

Encontramos uma divergência na fala dos sujeitos quanto ao envolvimento com militâncias estudantil, sindical e política, uma vez que entendem que docentes engajados nessas atividades inflamam discursos que nem sempre condizem com a prática pedagógica.

Tanto que Dubar (2009) ressalta que essa identidade é denominada de militante, partidária, associada e ligada às instituições que legitimam e defendem bandeiras de lutas por meio de agrupamentos de pessoas com as mesmas intenções.

Percebemos outra convergência, quando os docentes reconhecem uma identidade profissional pautada na Ciência da Motricidade Humana e na compreensão do ser humano na sua totalidade, como a melhor teoria para embasar a formação inicial do curso de EF. Esta é nossa posição dentro do debate epistemológico da área, defendendo a tese de que, caso a identidade profissional do professor esteja sustentada pelas bases que esta ciência revela, possivelmente estejamos prestes a definir seu objeto de estudo, bem como direcionar olhares que compreendam o ser humano que se movimenta intencionalmente na perspectiva da superação.

A Ciência MH nos convida a cultivar e direcionar para a totalidade humana, visando o corpo, o espírito, a natureza, a sociedade e a cultura. O estandarte da formação discente não é somente a ação objetiva ou o desenvolvimento motor, mas a compreensão do corpo como uno, com suas unidades genéticas, fisiológicas, anatômicas, culturais, sociais, espirituais e psicológicas.

Questionamos se o docente que atua no Curso faz leituras, aprofundamento, tem conhecimento do que essa ciência propõe para o campo da EF? Por que um professor, ao ingressar em um curso que apresenta uma proposta, não deveria apropriar-se do que foi pensado e estruturado coletivamente pelos antigos docentes? Tais reflexões nos fazem pensar na seguinte pauta: Será que este grupo de docentes 
realiza discussões sobre a questão episteme do PPC, procurando um consenso do viés mais indicado para o curso de EF?

Fica evidente, pelos dados da pesquisa, que há uma pulverização de teorias discutidas pelos docentes em sala de aula, como foi apresentado na fala dos sujeitos, o que dificulta ao próprio discente ter um posicionamento de concordância ou não sobre o que é trabalhado, e ter influência sobre aquilo que assumirá como identidade profissional.

Sob essa perspectiva, a área da EF não tem definido seu objeto próprio. No campo da formação, as várias modalidades de pesquisa apontam uma diversificação de conhecimentos nesta área. Há a necessidade da constituição de um campo de estudo autônomo, ou seja, uma comunidade de pesquisadores que assinale uma linguagem e uma comunicação própria, por meio das pesquisas que buscam o conhecimento e a formação.

Vale ressaltar um estudo de Pires et al (2017) que aponta a identidade docente é discutida a partir dos tempos e espaços das histórias de vida para melhor compreender as múltiplas identidades possíveis e encontradas na trajetória profissional de professores de Educação Física, corroborando com nossos achados. Validando a ideia de que na formação inicial é que a identidade se estabelece.

Portanto, defendemos que área da EF assuma esse objeto de estudo e adote essa ciência nas faculdades, de modo a estimular que a forma de pensar e agir interprete uma prática que projete a teoria e não vice-versa. A identidade profissional dos futuros professores de EF pode ser evidenciada de forma a transformar as atividades do ser humano em uma práxis que propicie mudanças e estados melhores na sua vida cotidiana.

\section{CONCLUSÕES}

No campo do conhecimento científico, toda trilha iniciada faz-nos despertar para o quanto necessitamos aprofundar e aperfeiçoar aquilo que apreciamos: a essência do 
ser humano, a nossa identidade. E, principalmente, a identidade profissional do professor de EF.

A identidade profissional do professor de Educação Física está relacionada a vários contextos. Um deles são as inúmeras relações entre o corpo, os grupos sociais, as práticas corporais, os campos de atuação, as questões sociais, filosóficas e humanas, uma vez que comparecem, na prática pedagógica, nos ambientes formais e não formais que envolvem a atuação desse profissional.

A EF é uma área que oferece cenários profissionais diferenciados para o professor atuar, o que faz necessário que os docentes, a partir das identidades assumidas, demonstrem todas essas possibilidades e sua importância nos contextos apresentados. Não há como pensar em uma formação acadêmica inicial sem entrelaçar os diversos âmbitos que a área permite discutir.

O corpo docente de uma faculdade deve ter um envolvimento com as demandas da área, propiciando discussões que conduzam o discente a relacionar o campo teóricocientífico com os saberes da prática. Nosso estudo revela que docentes com várias identidades tendem a reproduzir nos discentes a dificuldade de compreender os diversos saberes a serem aplicados no campo de atuação.

É preciso ampliar o debate sobre essas pautas que demarcam o hiato existente entre o que o Projeto Pedagógico de Curso anuncia e aquilo que os docentes protagonizam em sala de aula, desafio possível de ser superado coletivamente.

\section{REFERÊNCIAS}

AMIGUINHO, A.; VALENTE, A.; CORREIA, H.; MANDEIRO, M. J. Formar-se no projecto e pelo projecto. In. CANÁRIO, R. (Org.). Formação e situações de trabalho. Portugal: Porto Editora, 2003, p. 101-116.

ANDRÉ, M.E.B.A. (Org.). Formação de professores no Brasil 1990-1998. Brasília: MEC/Inep/Comped, n. 6, 2002. Série Estado do Conhecimento. 364 p. 
BENTO, J. O. Corpo e Desporto: reflexões em torno desta relação. In: MOREIRA, W. W. (Org.) Século XXI: A era do corpo ativo. São Paulo: Papirus, 2006.

, J. O. Pelo regresso do desporto: ensaio epistemológico. In: BENTO, J. O.; MOREIRA, W. W. Homo Sportivus: O humano no homem. Belo Horizonte: Instituto Casa da Educação Física, 2012, p. 14-112.

BETTI, M. Educação Física e Sociedade: a Educação Física na escola brasileira. 2 ed. São Paulo: Hucitec, 2009.

BICUDO, M. A. V. (Org.). Pesquisa Qualitativa: segundo a visão fenomenológica. São Paulo: Cortez, 2011. 150 p.

BRZEZINSKI, I. Profissão professor: identidade, profissionalização docente. Brasília: Plano Editora, 2002. 196 p.

CAGIGAL, J. M. Obras Selectas. Volumes I, II e III. Comitê Olímpico Español e Asociación Española de Deportes para Todos. Madrid: Cadiz, 1996. 1206 p.

CASTELLANI FILHO, L. Educação Física no Brasil: a história que não se conta. 8 ed. Campinas: Papirus, 2003.

CHAUÍ, M. Convite à Filosofia. São Paulo: Ática, 2000.

CIAMPA, A. A história de Severino e a história de Severina. São Paulo: Brasiliense, 1994.

DARIDO, S. C. Educação Física na Escola: questões e reflexões. Rio de Janeiro: Guanabara Koogan, 2003. 90 p.

DUBAR, C. A sociologia do trabalho frente à qualificação e à competência. Revista Educação \& Sociedade, Campinas, v.19, n. 64, p.01 -16, set. 1998.

C. A crise das identidades: Interpretação de uma mutação. São Paulo: Editora USP, 2009. 279 p. 
FRANYUTI, M. L. S., La concepción pedagógica de Pierre Parlebás. 2009. Disponível em: $<$ http://www.cpar.sep.gob.mx/dgef/htmlecturas/Otras/pierre_parlebas.html> Acesso em: 06 set. 2004.

GAIO, R.; CARVALHO, R. B.; SIMÕES, R. Métodos e técnicas de pesquisa: a metodologia em questão. In: GAIO, R. (Org.) Metodologia de pesquisa e produção de conhecimento. Petrópolis, Rio de Janeiro: Vozes, 2008, p. 147-171.

GALLARDO, J. S. P. (Org.). Educação Física: contribuições à formação profissional. 3 ed, ljuí, Editora Unijuí, 2000. 149 p.

GARCÍA, M. C. Formação de Professores: para uma mudança educativa. Portugal: Porto Editora, 1999.

GHIRALDELLI JUNIOR, P. Infância, escola e modernidade. São Paulo: Cortez, 1987.

GOODSON, I. F. Dar voz ao professor: as histórias de vida dos professores e o seu envolvimento profissional. In: NÓVOA, A. (Org.) Vidas de professores. Porto, Portugal: Porto Editora, 2000, p. 63-77.

GUERRA, I. C. Pesquisa Qualitativa e Análise de Conteúdo. Portugal: Principia, 2010.

GUIMARÃES, V. S. Formação de professores: Saberes, identidade e profissão. Campinas, São Paulo: Papirus, 2004. 119 p.

IMBERNÓN, F. Formação docente e profissional: formar-se para a mudança e a incerteza. 7 ed. São Paulo: Cortez, 2009.

LEMOS, K. R. F.; FRANÇA, S. M. M.; MACHADO, V. M. Tornar-se professor: um olhar sobre a prática docente. In: BRZEZINSKI, I. Profissão professor: identidade, profissionalização docente. Brasília: Plano Editora, 2002, p. 145-158. 
MARTINS, J.; BICUDO, M. A. V. Estudos sobre existencialismo, fenomenologia e educação. São Paulo: Moraes, 1983.

MARQUEZE, E. C.; MORENO, C. R. de C. Satisfação no trabalho e capacidade para o trabalho entre docentes universitários. Revista Psicologia em Estudo. Maringá, v. 14, n.1, p. 75-82, 2009.

MESQUITA, I.; JONES, R.; FONSECA, J.; SILVA, L. M. Nova abordagem na formação de treinadores: o que mudou e por quê? In: NASCIMENTO, J. V.; FARIAS, G. O. (Orgs.) Construção da Identidade Profissional em Educação Física: da formação à intervenção. Florianópolis: Ed. da UDESC, 2012, p. 41-60.

MOREIRA, W. W. Formação Profissional em Ciência do Esporte: Homo Sportivus e Humanismo. In: BENTO, J. O.; MOREIRA, W. W. Homo Sportivus: O humano no homem. Belo Horizonte: Instituto Casa da Educação Física, 2012, p. 111-172.

W. W.; SIMÕES, R.; PORTO, E. Análise de conteúdo: técnica de elaboração e análise de unidades de significado. Revista Brasileira Ciência e Movimento, v. 14, n 4, p. $104-114,2005$.

W. W. (Org.). Século XXI: A era do corpo ativo. São Paulo: Papirus, 2006.

NASCIMENTO, C. C. do. Inezil Penna Marinho: o tempo de uma história. In: FERREIRA NETO, A. (Org.). Pesquisa histórica na Educação Física. Volume 02, Vitória: UFES, 1997.

OLIVEIRA, V. M. de. O que é Educação Física. São Paulo: Editora Brasiliense, 2008 (Coleção Primeiros Passos). 111 p.

PARLEBÁS, P. Elementos de Sociologia del Deporte. Malaga: Universidad Internacional Deportiva de Andalucia, 1988.

P. Jeux, sports et sociétes: lexique de praxéologie motrice. Paris: Instituto du sport et de l'éducation physique, 1999. 
PEREIRA, L. L. S.; MARTINS, Z. I. O. A identidade e a crise do profissional docente. In: BRZEZINSKI, I. Profissão professor: identidade, profissionalização docente. Brasília: Plano Editora, 2002, p. 113-134.

PIRPES, V.; NASCIMENTO, J. V;; FARIAS, G. O.; SUZUKI, C.C. M. Identidade docente e eeducação física: um estudo de revisão sistemática. Revista Portuguesa de Educação. Vol. 30 n.1 junh., 2017.

SÉRGIO, M. Motricidade Humana: contribuições para um paradigma emergente. Blumenau, SC: Furb, 1995 (Coleção Epistemologia e Sociedade). 155 p.

M. Um corte epistemológico: da Educação Física à Motricidade Humana. 2 ed. Lisboa: Instituto Piaget, 1999.

M. Alguns olhares sobre o corpo. Lisboa: Instituto Piaget, 2003. 150 p.

M. A racionalidade epistêmica na Educação Física do século $X X$. In: SÉRGIO, M.; ROSÁVRIO, T.; FEITOSA, A. M.; ALMADA, F; VILELA, J.; TAVARES, V. O Sentido e a Ação. Lisboa: Instituto Piaget, 2008, p. 13 -30.

SEVERINO, A. J. Metodologia do trabalho científico. 23 ed. São Paulo: Cortez, 2007.

TARDIF, M. Saberes profissionais dos professores e conhecimento universitário: elementos para uma epistemologia da prática profissional dos professores e suas consequências em relação à formação para o magistério. Revista Brasileira de Educação, n 13, p. 05-24, 2000.

, M. Saberes docentes e formação profissional. Petrópolis, Rio de Janeiro: Vozes, 2002.

TOJAL, J. B. A. G. Da Educação Física à Motricidade Humana: a preparação do profissional. Lisboa, Portugal: Instituto Piaget, 2004. 162 p. 
ZEICHNER, K. A formação reflexiva de professores: ideias e práticas. Lisboa: Educa, 1993.

WHO, Organização Mundial de Saúde (OMS). Definição de saúde. Disponível em: $<$ http://www.who.int/countries/bra/es> Acesso em: 6 jan. 2013, 15:36:40

3. Atual Ensino Fundamental.

4. Atual Ensino Médio.

5. Escola Normal que visava a formação de professores do nível primário e secundário (BETTI, 2009).

6. A partir de 1930, é que se iniciam as concepções que influenciaram o contexto histórico da EF, sendo elas: higienista, militarista, esportivista e pedagógica (DARIDO, 2003).

7. Historiador que realiza um balanço historiográfico da EF no Brasil, por meio de quatro volumes publicados em 1943, com mais de mil páginas cada um.

8. Diretor do Instituto Nacional de Educación Física de Madrid, Espanha, e presidente da Escola Superior de EF (Écoles Normales Supérieures d'Education Physique), França.

9. No decorrer do texto, grafaremos as palavras desporto e esporte como sinônimas, sendo desporto utilizado quando as referências são do contexto espanhol, e esporte quando associadas ao contexto português.

10. Professor de EF, sociólogo, psicólogo, linguista francês, dirigiu durante vinte anos o Instituto Nacional de Desporto da França; atualmente é responsável pelo Laboratório de Jogos Desportivos e Ciências da Ação Motriz na Faculdade de Sociologia da Universidade de Sorbonne, em Paris, França (FRANYUTI, 2004).

11. Professor e médico estudioso dos sistemas cerebrais e das relações com as funções motoras, tendo apresentado suas obras na década de 1970. 
12. Manuel Sérgio pertence à célula dos escritores do Partido Comunista Português. Estudou, com rigor, teóricos como Marx, Nietzsche e Freud. É licenciado em Filosofia pela Universidade Clássica de Lisboa e Doutor e Professor Agregado em Motricidade Humana, pela Universidade Técnica de Lisboa e do Curso de EF do Instituo Piaget, de Almada. É sócio da Associação Portuguesa de Escritores e autor e coautor de 40 livros e de inúmeros artigos, em revistas nacionais e estrangeiras. É professor catedrático convidado aposentado da Faculdade de Motricidade Humana da Universidade Técnica de Lisboa.

13. Professor Catedrático da Faculdade de Ciências do Desporto e da EF da Universidade do Porto, Portugal pertence à cadeira de Pedagogia do Desporto. Atualmente é Presidente do Conselho Diretivo da referida Faculdade, sendo responsável pelos cursos de Licenciatura e Mestrado na área de Pedagogia do Desporto.

14. Formas de trabalho e vida que ignoram a dimensão física, corporal e motora do homem.

15. A Organização Mundial de Saúde (OMS) define saúde não apenas como ausência de doença, mas como estado de equilíbrio de bem-estar físico, mental e social. Entendemos que essa definição é reducionista, porque defendemos o conceito de saúde como pluridimensional, ou seja, são vários os fatores que envolvem o conceito de saúde do ser humano, como: alimentação, situação econômica e financeira, hábitos de vida, entre outros. (http://www.who.int/countries/bra/es - Acesso em 06/01/2013).

Enviado: Janeiro, 2018.

Aprovado: Fevereiro, 2019. 